\author{
Magdalena Pataj \\ Uniwersytet Marii Curie-Skłodowskiej w Lublinie \\ ORCID: 0000-0003-1578-8075
}

\title{
Postawy internautów wobec szczepionek w dobie pandemii na przykładzie wybranych memów internetowych
}

\begin{abstract}
Streszczenie
Celem artykułu było określenie, jakie postawy wobec szczepionek przejawiają użytkounicy sieci u dobie pandemii. Przyjęto, że działania internautów mieszczą się w założeniach o aktywności użytkouników mediów, memy internetoue zaś są jednym ze sposobów manifestacji stosunku nadawców do określonych kuestii. W artykule skupiono się na teoriach aktywnego użytkownika mediów, przybliżono także zagadnienie memów internetouych jako kluczowej jednostki w prowadzonym badaniu. Materiałem do badań były komunikaty opublikowane na portalu Demotywatory.pl, które poddano analizie zawartości. Zebrany materiał podzielono ze uzględu na związek z koronawirusem. Następnie poszukiwano odpowiedzi na pytania o postawy internautów - czy są zwolennikami, czy przeciunikami szczepień, skupiono się także na wydźwięku poszczególnych przekazów. Uzyskane wyniki pozwalają na określenie stosunku uybranej grupy do problemu szczepień, uświadamiają ponadto, że często kuestie zdrowotne są przyczynkiem do szerszej dyskusji (krytyki) na płaszczyźnie komunikowania politycznego.
\end{abstract}

Słowa kluczowe: szczepionki, memy internetowe, prosument, pandemia, komunikowanie o zdrowiu.

\section{The Attitudes of Internet Users to Vaccines During the Pandemic on the Basis of Selected Memes}

\begin{abstract}
The aim of this article is to discuss the attitudes exhibited by internet users to vaccines during the pandemic. It is assumed here that the activities of internet users fall within the general category of the activity of media users, while memes are a way to manifest the users' attitude to specific issues. The article employs the active audience theory and elaborates on the phenomenon of internet memes as a key category of research. The research material comprises messages posted on Demotywatory.pl that are subject to content analysis. The material is first categorized on the basis of its connection to the COVID-19 pandemic. Subsequently, the internet users' attitudes are determined - whether they support or reject vaccinations - and the implications of particular messages are analysed. The research results make it possible to pinpoint the attitude of a given group to the issue of vaccination. Further, they show that health issues are often a starting point for a broader discussion (and critique) on the level of political communication.
\end{abstract}

Keywords: vaccines, memes, prosumer, pandemic, health communication. 


\section{Wprowadzenie}

Internet jest skomplikowaną płaszczyzną komunikacji, dzięki której użytkownicy mediów mogą korzystać z różnych narzędzi pozyskiwania informacji, wymiany treści oraz tworzenia przekazów zgodnie ze swoimi potrzebami. Kreacyjna rola mediów

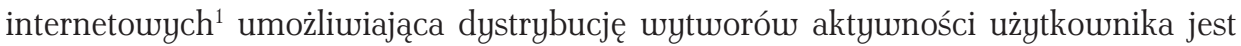
dla mnie szczególnie interesująca $w$ kontekście komunikowania o zdrowiu, a precyzyjniej - dyskusji, która toczy się wokół (nie)zasadności szczepień związanych z epidemią koronawirusa ${ }^{2}$. W artykule skupię się na memach internetouych, które dotykają wywołanego tematu. Interesujące będą dla mnie postawy internautów względem szczepień, sposoby wyrażania swoich opinii, kompetencje medialne i zdrowotne użytkowników (na podstawie sposobów argumentacji, krytyki). Materiał badauczy będzie analizowany z perspektywy teorii mediów, w których akcentowana jest aktywność odbiorców (postrzeganych jako prosumenci) ${ }^{3}$ oraz koncepcji kompetencji zdrowotnych ${ }^{4}$.

\section{Metodologia}

Celem artykułu jest refleksja nad sposobem prowadzenia dyskusji dotyczącej szczepień przeciuko COVID-19 (który jest wywoływany przez wirusa SARS-CoV-2) w Polsce. Dyskusji specyficznej, ponieważ toczącej się w mediach internetowych pomiędzy

\footnotetext{
${ }^{1}$ Rozumiana u sensie postulatywnym. Kuestia rzeczywistej skali aktywności internautóu nie jest przedmiotem badania, aczkolwiek stanowi ciekawe pole do analiz. Por. M. Szpunar, Nowe-stare medium Internet między tworzeniem nowych modeli komunikacyjnych a reprodukowaniem schematów komunikowania masowego, Wydawnictwo IFiS PAN, Warszawa 2012, https:// uwu.magdalenaszpunar.com/_pliki/Nowe-stare\%20medium_Szpunar.pdf (dostęp: 11.04.2021). ${ }^{2}$ W Polsce ze stanem epidemii mamy do czynienia od marca 2020 roku. Patrz: Rozporządzenie Ministra Zdrowia z dnia 20 marca 2020 roku u sprawie ogłoszenia na obszarze Rzeczypospolitej Polskiej stanu epidemii, Dz. U. 2020 poz. 491, z późn. zm.

${ }^{3}$ Zob. P. Siuda, Mechanizmy kultury prosumpcji, czyli fani i ich globalne zróżnicowanie, „Studia Socjologiczne" 2012, nr 4(207), s. 109-132, http://piotrsiuda.com/wp-content/uploads/2015/01/ Piotr_Siuda_Mechanizmy_kultury_prosumpcji.pdf (dostęp: 22.03.2021).

${ }^{4}$ Zob. D. Nutbeam, Health literacy as a public health goal: a challenge for contemporary health education and communication strategies into the 21st century, „Health Promotion International" 2000, Vol. 15(3), s. 259-267, https://doi.org/10.1093/heapro/15.3.259 (dostęp: 21.03.2021). O koncepcji kompetencji zdrowotnych pisałam m.in. w artykule Komunikowanie o zdrowiu w Polsce na przyktadzie akcji „Nie-bo-rak” [w:] Kobiety w sferze publicznej. Perspektywy interdyscyplinarne problemu, red. M. Pataj, Wydawnictwo Adam Marszałek, Toruń 2017, s. 215-229. W literaturze można spotkać przykłady zachowań prosumenckich lokowanych na płaszczyźnie zdrowotnej. G. Ritzer oraz N. Jurgenson jako przykład prosumcji uskazują m.in. autodiagnozę. Autorzy wymieniają m.in. testy ciążowe, domoue pomiary ciśnienia krwi. Prosumentem jest więc osoba wykorzystująca narzędzia do samodzielnego diagnozouania bez konieczności angażowania specjalisty. G. Ritzer, N. Jurgenson, Production, Consumption, Prosumption. The nature of capitalism in the age of the digital 'prosumer', „Journal of Consumer Culture" 2010, Vol. 10(1), s. 18, https://journals.sagepub.com/doi/pdf/10.1177/1469540509354673 (dostęp: 22.03.2021).
} 
osobami, które w większości nie są specjalistami ${ }^{5}$ w dziedzinie (a przynajmniej nie uskazują takiej przynależności), natomiast jako sposób komunikacji uybrały formę memów internetowych. Materiał badawczy stanowiły materiały zamieszczone na stronie Demotywatory.pl. Wybór nie był przypadkowy, portal jest wskazywany jako najpopularniejszy w swojej kategorii ${ }^{6}$. Po wpisaniu haseł „szczepionka” i „szczepienia” oraz zastosowaniu cezury początkowej określonej na 4 marca 2020 roku , końcowej zaś na 21 marca 2021 roku $^{8}$, otrzymałam 480 odpowiedzi ${ }^{9}$. Pod uwagę wzięłam uszystkie uzyskane, niepoutarzające się wyszukania. Zebrany materiał podzieliłam ze uzględu na stosunek użytkownika do problemu szczepień. Z uwagi na to, że memy internetowe traktuję jako przykład komunikatu multimodalnego, w badaniu przeanalizowałam warstwę werbalną, audialną oraz wizualną przekazów (biorąc pod uwagę na przykład intencje i konsekwencje czerpania z zasobu kulturowego). W moim odczuciu tylko uuzględnienie wszystkich modusów i relacji pomiędzy nimi pozwala na określenie znaczeń płynących z tego typu przekazów.

\section{O aktywnym użytkowniku}

Mówienie o memach internetowych wymaga spojrzenia na te teksty jako przykłady manifestowania aktywności współczesnego człowieka, który wykorzystuje kanały komunikacji w specyficzny, czynny sposób. Pojawienie się nowych mediów rozwinęło perspektywę myślenia o prosumencie. Jako prekursora pojęcia uskazuje się Alvina Tofflera i jego Trzecia falę ${ }^{10}$. W publikacji Toffler dokonuje periodyzacji historii na trzy etapy (fale). Futurysta widzi trzecią falę jako świat, w którym następuje decentralizacja, „odmasowienie”, różnorodność i fragmentaryzacja płaszczyzn ludzkiej aktyuności. Autor stwierdza, że „w nowym społeczeństwie standardowa kultura masowa ustąpi miejsca odmasowionym i zróżnicowanym środkom wymiany informacji; każdy będzie mógł nadawać, a nie tylko odbierać informacje" ${ }^{11}$. Należy się zgodzić z tym, że dokonała się zmiana u sposobie korzystania z mediów. Odbiorca ma możliwość tworzenia

\footnotetext{
${ }^{5}$ Należy zaznaczyć, że wśród analizowanych komunikatów pojawiały się także takie, których autorzy podkreślali suoją przynależność do zawodów medycznych.

${ }^{6}$ tw, Serwisy z humorem dalej traca popularność. Najbardziej w dót Joemonster i Kwejk (TOP10), https://wuw.wirtualnemedia.pl/artykul/serwisy-z-humorem-dalej-traca-popularnosc-najbardziej-w-dol-joemonster-i-kwejk-top10) (dostęp: 11.04.2021).

7 Tego dnia oficjalnie wykryto pieruszy przypadek koronawirusa w Polsce.

8 Z uwagi na rozwojową sytuację epidemii data końcowa określona jest jako maksymalnie aktualna ze względu na czas pisania tego tekstu.

9 Jeśli dany mem internetowy pojawił się podwójnie w wyszukiwaniach, np. z uwagi na przypisanie mu obu haseł, uwzględniałam go jako jeden komunikat.

${ }_{10}^{10}$ G. Ritzer, N. Jurgenson, Production, Consumption, Prosumption..., s. 17. Należy zastrzec, że zauważenie uymienności (łączności) ról producenta i konsumenta jest jeszcze starsze. Zob. G. Ritzer, P. Dean, N. Jurgenson, The Coming of Age of the Prosumer, „American Behavioral Scientist” 2012, Vol. 56(4), s. 379, https://doi.org/10.1177\%2F0002764211429368 (dostęp: 9.04.2019). ${ }^{11}$ A. Toffler, Trzecia fala, przeł. E. Woydyłło, Państwowy Instytut Wydauniczy, Warszawa 1997, s. 8.
} 
i dystrybucji treści poza wielkimi (lub mniejszymi) instytucjami medialnymi, co z kolei rodzi nową jakość w badaniach nad komunikacją społeczną. W swojej publikacji Toffler dostrzega interesujące zjawisko rozdrobnienia społeczeństwa ze względu na „punkty widzenia”, co jest konsekwencją zmian charakterystycznych dla świata „trzeciej fali”. Stwierdza:

Całe społeczeństwo przestawia się na różnorodność, która jest dominującą cechą trzeciej fali, a nowe środki komunikacji odzwierciedlają ten proces, róunocześnie go przyspieszając. Wyjaśnia to częściowo fakt, dlaczego coraz bardziej różnicują się opinie na uszelkie tematy, od muzyki począuszy, a na polityce skończyuszy ${ }^{12}$.

Zdanie wydaje się wyjątkowo trafne, nawet z perspektywy lat, które upłynęły od jego wypowiedzenia. Autor mówi o „kulturze impulsów”, sugerując brak stabilności i ciągłą dyskusję z treściami pretendującymi do miana uniwersalnych. Wyjaśnia, że:

w wymiarze indywidualnym człowieka osaczają i zeusząd atakują uyobrażenia fragmentaryczne, sprzeczne lub niepowiązane ze sobą, które podważają jego dawne idee i trafiają do świadomości w postaci jakiś niepełnych lub wyrwanych z kontekstu elektronicznych impulsów ${ }^{13}$.

W perspektywie realizowanych w artykule badań jest to cenna uwaga. Faktycznie wydaje się, że poruszamy się w świecie informacji coraz częściej pozbawionych ciągłości, ulegających dekontekstualizacji. Zarazem nowe media dają nam możliwość tworzenia i rozpouszechniania takich informacji, czego przykładem wydają się między innymi właśnie memy internetoue dotyczące szczepionek.

W nawiązaniu do teorii mediów najbardziej interesujące moim zdaniem są badania osadzające aktywnego użytkounika w rzeczywistości internetu, gdzie widoczne jest między innymi silne zaangażowanie użytkowników w tworzenie i przetwarzanie treści ${ }^{14}$. George Ritzer, Paul Dean oraz Nathan Jurgenson, wskazując na zjawiska, które można uznać jako przykład prosumpcji, wymieniają internet 2.0, traktowany jako przestrzeń dającą możliwość kreowania treści przez użytkowników ${ }^{15}$. Przez ów pryzmat można spojrzeć róunież na memy internetowe. Perspektywa prosumenta, upisująca się w logikę tworzenia i dystrybucji przekazów tego typu, pozuala na namysł nad kompetencjami zdrowotnymi współczesnych użytkowników internetu. Nadawcy, podejmując w swojej działalności tematy zdrowotne, działają zgodnie z ideą promocji zdrowia różnych instytucji (wspierając zamysł szczepień) lub stoją do niej w opozycji. Wykorzystując argumenty racjonalne bądź emocjonalne, mogą oddziaływać na postawy odbiorców i przekonywać ich do określonych zachowań na płaszczyźnie zdrowotnej.

\footnotetext{
12 Ibidem, s. 261.

${ }^{13}$ Ibidem.

${ }^{14}$ G. Ritzer, N. Jurgenson, Production, Consumption, Prosumption..., s. 19-20.

${ }^{15}$ G. Ritzer, P. Dean, N. Jurgenson, The Coming of Age of the Prosumer..., s. 385.
} 
Mimo że we uspółczesnych pracach nawiązania do Tofflerouskiej wizji są wciąż widoczne, pojawiają się „aktualizacje” pojęcia, o których również należy uspomnieć. Wartym zauważenia jest między innymi produser, termin - jak się wydaje - precyzyjniej niż prosument oddający specyfikę aktywności internautów. Jan Kreft, odwołując się między innymi do ustaleń Axela Burnsa, wskazuje, że

koncepcja produsera podkreśla zaangażowanie społeczności we wspólne tworzenie i przesyłanie informacji oraz wiedzy, zanik roli konsumenta, zacieranie się różnicy między producentem i użytkounikami oraz dzielenie się wiedzą, także - co istotne - wówczas, gdy nie są oni śuiadomi swej roli ${ }^{16}$.

Wyznacznikami takiej postawy są więc: możliwość tworzenia, przekształcania oraz przekazywania treści cyfrowych. Mowa również o uspółpracy pomiędzy użytkownikami, strategiami uymiany zasobów informacyjnych. Wspomniany już Kreft, omawiając charakter zjawiska, wymienia między innymi działania użytkouników mediów cyfrowych, które są obliczone na współpracę i dzielenie zasobów, a nie na komercjalizację, równość użytkowników, wiarę u Jenkinsouską „zbiorową mądrość”, przekonanie, że aktywność jest silnie skorelowana z możliwościami i kompetencjami jednostki ${ }^{17}$. Z kolei Małgorzata Lisouska-Magdziarz przywołuje definicję prosumenta w rozumieniu „współczesnego użytkounika mediów masouych, używającego ich twórczo i budującego z dostarczanych przez nie treści własną tożsamość u sposób aktyuny, u stałej komunikacji z innymi i pod presją oceny podobnych sobie"18. Autorka odwołuje się także do użytego już ucześniej zagadnienia produser, rozumiejąc je jako tożsame z prosumentem ${ }^{19}$.

Przyjęcie wymienionych spojrzeń na uspółczesne media i ich użytkouników daje możliwość analizy aktywności internautów widzianych jako kreatywne, twórcze jednostki, które używają nowych mediów do wyrażania opinii, dyskusji, nakłaniania innych do swoich racji. Wydaje się, że ruch pro- i antyszczepionkowców może rozwijać się

\footnotetext{
${ }_{16}$ J. Kreft, Konsekwencje wspóttworzenia wartości w mediach przez użytkowników, „Zarządzanie w Kulturze" 2013, nr 14, z. 4, s. 353, http://www.ejournals.eu/Zarzadzanie-w-Kulturze/ Tom-14-2013/14-4-2013/art/1678/ (dostęp: 23.03.2021). Por. M. Krzanicki, Gracz - prosument w cyfrowej rzeczywistości. Rewolucja czy ewolucja?, „Kuartalnik Nauk o Mediach” 2015, nr 1, http://knm.uksw.edu.pl/gracz-prosument-cyfrowej-rzeczywistosci-rewolucja-ewolucja/ (dostęp: 23.03.2021).

17 J. Kreft, Za fasada spoteczności. Elementy zarządzania nowymi mediami, Wydaunictuo Uniwersytetu Jagiellońskiego, Kraków 2015, s. 62. Autor podaje cechy za: A. Burns, Blogs, Wikipedia, Second Life, and Beyond. From Production to Produsage, Peter Lang, New York 2008.

${ }^{18}$ M. Lisouska-Magdziarz, Feniksy, tabędzie, motyle. Media i kultura transformacji, Wydawnictwo Uniwersytetu Jagiellońskiego, Kraków 2012, s. 80.

${ }^{19}$ Ibidem, s. 80.
} 
dzięki takiej postawie. Użytkounik, wykazując wysokie kompetencje komunikacyjne ${ }^{20}$, tworzy przekazy, w których promuje określone postawy, często też krytycznie odnosi się do treści już istniejących.

\section{O memach internetowych}

Memy internetowe są przedmiotem zainteresowania badaczy różnych dziedzin (m.in. medioznawców, politologów, językoznawców) ${ }^{21}$ i stanowią dość nową (niewyeksploatowaną) płaszczyznę refleksji naukowej. W literaturze dotyczącej wybranego tematu autorzy, rozpoczynając wywód o memach internetouych, sięgają do pozycji Richarda Dawkinsa czy Susan Blackmore, uznawanych za prekursorów wywodu o memach ${ }^{22}$. Na potrzeby artykułu warto doprecyzować co mam na myśli, pisząc „mem internetowy”. Odwołując się do ustaleń Jakuba Nowaka, przyjmuję definicję memu internetowego widzianego jako: „tekst kultury, który zyskał popularność przez (z reguły) spontaniczną dystrybucję online, odbywającą się przynajmniej do peunego stopnia niezależnie od przemysłów kultury, z których symbolicznego repozytorium czerpią twórcy i odbiorcy memów"23. W przytoczonych słowach rysuje się charakterystyka memu internetowego, rozumianego jako przekaz cyfrowy (tworzony i rozpouszechniany dzięki narzędziom cyfrowym), w którym są wykorzystywane zasoby kulturowe (na poziomie jego kreacji i odbioru) traktowane jako zasób, z którego korzystamy na warunkach innych niż określone przez nadawcę pierwotnego ${ }^{24}$. Uważa się, że jedną z funkcji memów internetowych jest intencja ludyczna - mem internetouy często jest rozumiany w kategoriach żartu, zabauy, rozmieszczania lub ośmieszania.

Magdalena Kamińska zauważa, że pojęcie „jest potocznie używane przez internautów na oznaczenie popularnego semiotycznego kompleksu transmitowanego via ICT, najczęściej w formie tak zwanego żartu internetowego" ${ }^{25}$. Nie da się jednak

${ }^{20}$ Określam je jako wysokie, ponieważ nadawca musi uykazywać się umiejętnościami u zakresie tworzenia i dystrybucji przekazów memouych (kompetencje medialne), czerpie z zasobu komunikatów o zdrowiu, komentując je i prezentując swoją postawę wobec nich lub wykorzystując je do szerszej dyskusji, np. na tematy polityczne czy społeczne.

${ }^{21}$ Por. L. Shiffman, Memes in a Digital World: Reconciling with a Conceptual Troublemaker, „Journal of Computer-Mediated Communication” 2012, Vol. 18, s. 363, https://onlinelibrary. wiley.com/doi/epdf/10.1111/jcc4.12013 (dostęp: 23.03.2021).

${ }^{22}$ Patrz np. M. Kamińska, Niecne memy. 12 wykładów o kulturze internetu, Wydawnictwo Galeria Miejska Arsenał, Poznań 2011, s. 60; J. Nowak, Memy internetowe: teksty (cyfrowej) kultury językiem krytyki społecznej [w:] Współczesne media. Język mediów, red. I. Hofman, D. Kępa-Figura, Wydaunictuo Uniwersytetu Marii Curie-Skłodouskiej, Lublin 2013, s. 239; K. Piskorz, Internetowe memy - hieroglify XXI wieku [w:] Wspótczesne media..., s. 227; L. Shiffman, Memes in a Digital World..., s. 363-364. A.A. Niekrewicz, Od schematyzmu do kreacyjności. Język memów internetowych, Wydawnictwo Państwowej Wyższej Szkoły Zawodowej im. Jakuba z Paradyża, Gorzów Wielkopolski 2015, s. 13.

${ }^{23}$ J. Nowak, Memy internetowe..., s. 240. Należy doprecyzować, że badacz u przywołanym artykule patrzy na memy internetowe przez pryzmat brytyjskich studiów kulturowych.

${ }^{24}$ Ibidem.

${ }^{25}$ M. Kamińska, Niecne memy..., s. 61. 
zignorować waloru komentującego rzeczywistość. Memy internetoue są sposobem na wyrażanie opinii internautów, często stanowią formę sprzeciuu wobec na przykład decyzji politycznych ${ }^{26}$. Warte odnotowania jest także założenie „wyczerpania” memu. Kamińska wskazuje, że atrakcyjność tego typu przekazów ma związek między innymi z autentycznością (wynikającą ściśle z definicji memu). Otóż popularność memu wiąże się z działalnością „zuykkłych” internautów. W momencie przejęcia memu internetouego przez instytucje komercyjne w celach zarobkowych, mem traci na wartości, a w końcu zniknie zainteresowanie nim ${ }^{27}$. W ujęciu tematu artykułu są także narzędziem, dzięki któremu użytkownicy mogą wyrazić swój (często krytyczny) stosunek do szczepień. Interesują mnie więc nie tylko postawy, lecz także sposób ich manifestowania.

\section{Wyniki}

Jak wskazywano we wcześniejszych częściach tekstu, zwolennicy i przeciunicy szczepień wykorzystują formę memów internetouych do wyrażania opinii na ów temat. Posługują się przy tym różnymi strategiami komunikacyjnymi czy sposobami argumentacji. Zakładają także pewien stopień kompetencji kulturowych odbiorców czerpiąc z zastanych tekstów kultury, wykorzystując fragmenty przekazów medialnych, liczą na zgodne z ich intencją odczytanie (zwłaszcza gdy warstwa werbalna odczytana dosłownie i bez uuzględnienia innych kodów ma inne znaczenie niż potraktowanie memu internetowego jako przekazu multimodalnego, na którego sens składają się komunikaty werbalne, wizualne czy audialne).

Pieruszą kategorią, która interesowała mnie podczas analizowania zebranego materiału, była postawa internautów wobec szczepień przeciuko COVID-19. Zebrany materiał podzieliłam na przekazy, które bezpośrednio lub w domyśle dotyczą tej szczepionki oraz na pozostałe, odnoszące się albo do innych rodzajów szczepień, albo wykorzystujące metaforyczność bądź polisemiczność słowa „szczepionka”. W pieruszej grupie umieściłam $450^{28}$ memów, w drugiej - 3029. Zdecydowana większość memów w badanym czasie nawiązywała do tematyki koronawirusa. Okres pandemii uyraźnie wpłynął na tematy podnoszone w dyskursie medialnym, również na te odnoszące się

${ }_{26}$ Zob. J. Nowak, The Good, the Bad, and the Commons: A Critical Review of Popular Discourse on Piracy and Power During Anti-ACTA Protests, „Journal of Computer-Related Communication” 2016, Vol. 21(2), s. 177-194, https://onlinelibrary.wiley.com/doi/full/10.1111/ jcc4.12149 (dostęp: 23.03.2021).

${ }_{27}$ M. Kamińska, Niecne memy..., s. 66. Ciekawe są strategie wypierania takich przekazów. Autorka uskazuje na mechanizmy „karania” internautów powielających mem internetowy, który ulega likwidacji.

${ }^{28}$ W tej grupie zdecydowałam się umieścić także mem, który co prawda dotyczył szczepionki przeciu grypie, ale przedstawionej jako bezpośredni czynnik odpowiadający na uzrost zachorowań u październiku 2020 roku.

${ }^{29}$ Komunikaty te dotyczyły szczepień na inne choroby (m.in. polio, ospę, różyczkę) lub odnosiły się np. do metafory szczepionki jako panaceum na przemoc domową. Wśród tych przekazów pojawiały się głosy popierające ideę szczepień, uyśmiewające postauy antyszczepionkowe lub podnoszące problemy osób, które nie chcą się szczepić. 
do szczepionek. Wydaje się, że wątpliwości dotyczące szczepień przeciuko innym chorobom stały się mniej ważne i kontrowersyjne - wynika to także z ich rzadszej obecności w mediach.

Spośród komunikatów pozostających w tematyce koronawirusa 298 włączyłam do grupy o uydźwięku popierającym ideę szczepień. Należy też zaznaczyć, że stopień poparcia był różny - od jawnych nawoływań do szczepienia się, traktowania szczepionki jako jedynej broni z wirusem, po mniej wyraźne komentarze dotyczące sytuacji w pandemii, w których jednak można było założyć pozytyuny stosunek autora do szczepień. Tematyka tych memów oraz cel, dla którego poustały, były różne. Co prauda 132 przypadki w tej grupie stawiały szczepienia w pozytywnym świetle, ale wydaje się, że intencja nadawcy obejmowała szersze kwestie. Komunikaty te były bouiem swojego rodzaju krytyką - władzy, różnych instytucji bądź osób czy decyzji politycznych. W tej grupie znalazły się ponadto memy negatyunie oceniające sposób i tempo szczepień, a także te, które odnosiły się (róunież krytycznie lub prześmieuczo) do sytuacji szczepień poza kolejką ${ }^{30}$. Spośród analizowanych przekazów 96 miało wydźwięk ośmieszający lub krytykujący teorie negujące istnienie wirusa lub zasadność szczepień, powody, dla których ludzie odmawiają szczepień lub argumenty, które przekonałyby ich do przyjęcia preparatu. Wskazywano między innymi na to, że odpowiednia suma pieniędzy lub nagrody nawiązujące do Gangu Śuieżaków ${ }^{31}$ przekonałyby sceptyków do zasadności szczepień. Parodiowano także obauy antyszczepionkowców dotyczące uprowadzenia w ich organizmy czipów, którymi ma sterować Bill Gates.

Natomiast 22 memy były poświęcone informacjom o szczepionce (sposobowi wytuarzania, testowania, działania; uskazywano także na wymagania obowiązujące przyjmujących preparat na przykład konieczność bycia trzeźuym). W tej grupie znalazły się także reakcje na fake newsy. W 16 przypadkach szczepionka była pokazana jako coś uyczekiwanego, symbol 2021 roku, nawet jeśli internauci, mimo pozytyunego stosunku do produktu, z pewną ulgą przyjmowali fakt, że inne państua będą się szczepiły przed Polską. Wskazywano również na to, że istnieją czynniki mogące zagrozić produkcji szczepionek (i to źle). Spośród badanych memów osiem odnosiło się do kuestii skuteczności i bezpieczeństwa szczepionek, które traktowano jako broń w walce z wirusem i guarant końca epidemii. W siedmiu przypadkach zachęcano do szczepień, posługując się mechanizmem autorytetu. Pokazywano na przykład, że osoby sławne przyjmują preparat, chcąc tym samym przekonać odbiorców do tego, że powinni zachować się w podobny sposób. W pozostałych przykładach wskazywano na pozytywny stosunek do szczepień przy jednoczesnej krytyce sposobu mówienia o nich w serwisach informacyjnych $\left(5^{32}\right)$, informowano o tym, że jest mało (niewystarczająco) szczepionek, ponadto podnoszono problem sabotowania szczepień poprzez niszczenie produktu przez osoby przekonane o jego szkodliwości (5). Nadawcy przekazywali informacje

${ }^{30}$ Chodzi o zaszczepienie poza kolejnością m.in. aktorów na Warszauskim Uniuersytecie Medycznym.

${ }^{31}$ Działania u ramach kampanii sieci Biedronka.

${ }^{32} \mathrm{~W}$ nawiasach podano liczbę memów internetouych. 
o liczbie już zaszczepionych (4), traktując to jako sposób na mobilizację społeczeństua. Wskazywano także (3), że Polacy świetnie radzą sobie z wytwarzaniem własnej lub podrabianiem obcej szczepionki, mimo że jednocześnie są niedofinansouyuwani (co było ocenione jako negatyuna okoliczność).

Takie zestawienie prowadzi do ciekawych wniosków. Memy internetowe stały się narzędziem do wyrażania suojego poparcia dla szczepień oraz zachęcania innych osób do tego, by się zaszczepiły. Jest to wynik kompetencji zdrowotnych jednostek - umiejętność wykorzystywania pojęć z zakresu medycyny, działania na rzecz promocji zdrowia (przy wykorzystaniu argumentóu racjonalnych, na przykład danych liczbouych, ustaleń naukowych czy emocjonalnych, tj. opinii, postaw). Ciekawe jest to, że część działań zachęcających do szczepień polegała nie na próbie informowania o ważkości takiego zachowania lub posługiwania się argumentami racjonalnymi, lecz na ośmieszaniu lub krytyce postaw antyszczepionkowych. Memy internetowe, w których nie negowano szczepień, były także wykorzystywane jako głos krytyczny w dyskusji osadzonej na innej niż zdrowotna płaszczyźnie. Mam tu na myśli te przekazy, które służyły (poza kwestią szczepień) wyrażeniu swojej dezaprobaty wobec działań politycznych. Wydaje się, że taką rolę pełni także część przekazów umieszczonych w grupie reprezentującej negatyuny bądź nieokreślony (lub neutralny) stosunek do szczepień.

Sprzeciu wobec idei szczepień zauważyłam w 102 przypadkach spośród badanej próby. W 36 tekstach skupiono się na niepożądanych odczynach poszczepiennych (mówiono tu m.in. o zgonach, uszczerbkach na zdrowiu), uskazywano na brak bezpieczeństua szczepionki, podkreślano także niewystarczające badania nad preparatem. Ponadto w przekazach uskazywano, że szczepienia leżą w interesie firm i rządów (18), natomiast fale epidemii i sam fakt powszechności szczepień (oraz praudopodobnie konieczności ich poutarzania) jest zaplanowany i służy realizacji partykularnych celów instytucji lub osób (Billa Gatesa). Internauci przedstawiali szczepienia w kategoriach przymusu bądź kary (18), podkreślali, że prowadzi to do niesprawiedliwego stworzenia podziału na osoby lepsze i uprzywilejowane (zaszczepione) oraz gorsze, z ograniczonym dostępem do różnych zasobów (niezaszczepieni). Dziesięć memów w badanej grupie odnosiło się do nieskuteczności szczepionki, która w zasadzie przed niczym nie chroni ${ }^{33}$. Ta sama liczba pojawiła się w przekazach, które u prześmieuczy sposób przedstawiały ideę szczepień. Wśród sceptycznych postaw nadawców podnoszono także argumenty uskazujące na to, że szczepionka poustała szybko i to podejrzane (3), osoby znane, które szczepią się jako przykład, tak napraudę udają i nie przyjmują specyfiku (3). Istnienie szczepionki było traktowane również jako jedno z nowych, niepożądanych zjawisk we uspółczesnym świecie (2), na róuni na przykład ze zbyt daleko posuniętą cyfryzacją życia społecznego, która zaburza stosunki międzyludzkie. Podnoszono także zapowiedzi przymusowych szczepień, na przykład pod groźbą utraty pracy (1) lub podstępów, które nakłonią sceptyczne osoby do przyjęcia substancji (1).

${ }^{33} \mathrm{~W}$ tej grupie umieściłam uspomniany ucześniej mem dotyczący korelacji pomiędzy szczepionką na grypę (a raczej jej nieskutecznością) a zachorowaniami na COVID-19 w październiku 2020 roku. 
W przywołanym zestawieniu widoczne jest to, że argumenty dotyczące obau przed skutkami ubocznymi szczepionki czy jej nieskuteczności (czyli bezpośrednio nawiązujące do koncepcji komunikowania o zdrowiu) nie są jedynymi. Sceptycyzm wobec produktu wynika oprócz tego z poczucia stosowania pewnego przymusu, który jest wywierany przez różne grupy interesu lub przekonania o tym, że w rzeczywistości są to działania zaplanowane, sterowane.

Trzecia grupa to przekazy, w których nie ustaliłam stosunku nadawcy do przedmiotu analizy, jednak sytuacja związana ze szczepieniami stała się podstawą (pretekstem) do komentowania rzeczywistości. Najczęściej (16) u sposób prześmieuczy przedstawiano różne sytuacje nawiązujące do procesu szczepień, w 15 przypadkach krytykowano władzę, decyzje polityczne oraz sposób szczepień. Pojawiły się także memy uskazujące na istnienie szczepień i rozdarcia nadawców uzględem decyzji o przyjęciu preparatu (4), ukazujące w zabawny sposób proces wytwarzania szczepionki (4). W trzech przypadkach umieszczono dane o szczepionkach bez wyraźnego zaznaczenia postauy nadawcy, poszukiwano również kruvi ozdrowieńców jako swoistej szczepionki. Ponadto informowano o bieżących decyzjach politycznych oraz planach dotyczących szczepień (2), nawiązywano do teorii spiskowych oraz krytykowano polityków (2), mówiono o pouszechności szczepień (1), interesach firm i państu (1), krytykowano sposób mówienia o szczepieniach w mediach (1), zauważano także, że istnieją zuolennicy i przeciunicy szczepień, ważne, by szanować zdanie każdego (1).

Jak zaznaczyłam wcześniej, stosunek nadaucy do szczepień w tym przypadku był nieoczywisty. Jednak ów problem prowokował dyskusję na tematy inne, czy to ośmieszające rzeczywistość, czy będące głosem krytycznym wobec sytuacji społeczno-politycznej.

\section{Podsumowanie}

Memy internetowe stanowią płaszczyznę manifestowania własnych postaw uzględem szczepień oraz nakłaniania do swojej wizji świata odbiorców. Jak wskazałam wcześniej, pandemia znacząco upłynęła na dyskusję w tym temacie - większość przekazów w omawianym czasie miała zuiązek z koronawirusem. Niezmienne pozostał jednak przedpandemiczny podział na osoby będące zwolennikami bądź przeciunikami szczepień. Argumenty używane przez strony były zróżnicowane. W analizowanych komunikatach pojawiały się zaróuno mające na celu uwiarygodnić przekaz dane (m.in. liczbowe lub/i mające wydźuięk opracowania naukowego), jak i treści emocjonalne. Należy zaznaczyć, że niektóre komunikaty wymagały wysokich kompetencji odbiorczych - poza tym, że tekst multimodalny sam w sobie jest skomplikowany w odbiorze, to należało wychwycić także na przykład nawiązania intertekstualne, odsyłające do zasobów kultury. Cytowany wcześniej Toffler uskazywał, że społeczeństwo przyszłości dzięki nowym mediom będzie coraz bardziej rozdrobnione, jeśli chodzi o postauy i opinie na różne tematy, same media zaś będą umożliwiały tworzenie i przepływ komunikatów 
o tym śuviadczących. Analizowany materiał uydaje się tego odzwierciedleniem. Badanie pokazało, jak wiele jest punktów widzenia na wywołany temat, natomiast kuestie zdrowotne są często ściśle powiązane ze sferą społeczno-polityczną. To potwierdza róunież spostrzeżenia przywoływanych badaczy dotyczące istoty memu internetowego. Traktowanie tego zjawiska wyłącznie w kategoriach żartu jest nieaktualne. Tego typu przekazy są także sposobem na manifestowanie suoich postaw politycznych, reagowaniem na bieżące kwestie społeczne, służą róunież nakłanianiu.

\section{Bibliografia}

Kamińska M., Niecne memy. 12 wykładów o kulturze internetu, Wydaunictwo Galeria Miejska Arsenał, Poznań 2011.

Kreft J., Konsekwencje wspóttworzenia wartości w mediach przez użytkowników, „Zarządzanie w Kulturze" 2013, nr 14, z. 4, s. 351-360, http://www.ejournals.eu/Zarzadzanie-w-Kulturze/ Tom-14-2013/14-4-2013/art/1678/ (dostęp: 23.03.2021).

Kreft J., Za fasada spoteczności. Elementy zarządzania nowymi mediami, Wydawnictuo Uniwersytetu Jagiellońskiego, Kraków 2015.

Krzanicki M., Gracz - prosument w cyfrowej rzeczywistości. Rewolucja czy ewolucja?, „Kwartalnik Nauk o Mediach” 2015, nr 1, http://knm.uksw.edu.pl/gracz-prosument-cyfrowej-rzeczywistosci-rewolucja-ewolucja/ (dostęp: 23.03.2021).

Lisouska-Magdziarz M., Feniksy, łabędzie, motyle. Media i kultura transformacji, Wydawnictwo Uniwersytetu Jagiellońskiego, Kraków 2012.

Niekrewicz A.A., Od schematyzmu do kreacyjności. Język memów internetowych, Wydawnictwo Państwowej Wyższej Szkoły Zawodowej im. Jakuba z Paradyża, Gorzów Wielkopolski 2015.

Nowak J., Memy internetowe: teksty (cyfrowej) kultury językiem krytyki społecznej [w:] Wspótczesne media. Język mediów, red. I. Hofman, D. Kępa-Figura, Wydawnictuo Uniwersytetu Marii Curie-Skłodouskiej, Lublin 2013.

Nowak J., The Good, the Bad, and the Commons: A Critical Review of Popular Discourse on Piracy and Power During Anti-ACTA Protests, „Journal of Computer-Related Communication" 2016, Vol. 21(2), s. 177-194, https://onlinelibrary.wiley.com/doi/full/10.1111/ jcc4.12149 (dostęp: 23.03.2021).

Nutbeam D., Health literacy as a public health goal: a challenge for contemporary health education and communication strategies into the 21st century, „Health Promotion International” 2000, Vol. 15(3), s. 259-267, https://doi.org/10.1093/heapro/15.3.259 (dostęp: 21.03.2021).

Pataj M., Komunikowanie o zdrowiu w Polsce na przyktadzie akcji „Nie-bo-rak”[w:] Kobiety w sferze publicznej. Perspektywy interdyscyplinarne problemu, red. M. Pataj, Wydawnictwo Adam Marszałek, Toruń 2017.

Piskorz K., Internetowe memy - hieroglify XXI wieku [w:] Współczesne media. Język mediów, red. I. Hofman, D. Kępa-Figura, Wydawnictuo Uniwersytetu Marii Curie-Skłodouskiej, Lublin 2013.

Ritzer G., Dean P., Jurgenson N., The Coming of Age of the Prosumer, „American Behavioral Scientist" 2012, Vol. 56(4), s. 379-398, https://doi.org/10.1177\%2F0002764211429368 (dostęp: 9.04.2019). 


\section{Magdalena Pataj}

Ritzer G., Jurgenson N., Production, Consumption, Prosumption. The nature of capitalism in the age of the digital 'prosumer', „Journal of Consumer Culture” 2010, Vol. 10 (1), s. 13-36, https://journals.sagepub.com/doi/pdf/10.1177/1469540509354673 (dostęp: 22.03.2021).

Rozporządzenie Ministra Zdrowia z dnia 20 marca 2020 roku u sprawie ogłoszenia na obszarze Rzeczypospolitej Polskiej stanu epidemii, Dz. U. 2020 poz. 491, z późn. zm.

Shiffman L., Memes in a Digital World: Reconciling with a Conceptual Troublemaker, „Journal of Computer-Mediated Communication" 2012, Vol. 18, s. 362-377, https://onlinelibrary.wiley. com/doi/epdf/10.1111/jcc4.12013 (dostęp: 23.03.2021).

Siuda P., Mechanizmy kultury prosumpcji, czyli fani i ich globalne zróżnicowanie, „Studia Socjologiczne" 2012, nr 4(207), s. 109-132, http://piotrsiuda.com/wp-content/uploads/2015/01/ Piotr_Siuda_Mechanizmy_kultury_prosumpcji.pdf (dostęp: 22.03.2021).

Szpunar M., Nowe-stare medium Internet między tworzeniem nowych modeli komunikacyjnych a reprodukowaniem schematów komunikowania masowego, Wydawnictwo IFiS PAN, Warszawa 2012, https://www.magdalenaszpunar.com/_pliki/Nowe-stare\%20 medium_Szpunar.pdf (dostęp: 11.04.2021).

Toffler A., Trzecia fala, przeł. E. Woydyłło, Państwouy Instytut Wydawniczy, Warszawa 1997. tw, Serwisy z humorem dalej traca popularność. Najbardziej $w$ dót Joemonster i Kwejk (TOP10), https://www.wirtualnemedia.pl/artykul/serwisy-z-humorem-dalej-traca-popularnosc-najbardziej-w-dol-joemonster-i-kwejk-top10) (dostęp: 11.04.2021). 